\title{
Mensuração da carga de trabalho de magistrados: uma análise comparativa do estudo realizado no Tribunal de Justiça do Estado do Rio Grande do Sul com experiências internacionais
}

\author{
Silvia Generali da Costa*, Cláudio Luís Martinewski**, Luciano José \\ Martins Vieira***, Nelson Michel**** e Renato Michel*****
}

\section{INTRODUÇÃO}

O número de processos que ingressam no Tribunal de Justiça do Estado do Rio Grande do Sul vem aumentando de forma significativa a cada ano, sendo que este aumento não é acompanhado, na mesma proporção, pelo ingresso de novos magistrados e servidores (Rio Grande do Sul, 2004). Do ponto de vista dos integrantes do sistema, é senso comum que o número de contratações de servidores não acompanha a demanda gerada pelo aumento do número de processos em tramitação (Brancher, 1998; Brancher; Costa, 1998). Independente da demanda, o quadro de magistrados e servidores tem envidado esforços no sentido da manutenção da qualidade dos serviços prestados à sociedade, muitas vezes através de esforços pessoais, aumento da jornada de trabatho e menor dedicação às áreas familiar, de lazer, esporte, saúde e cultura. Como resultado, a mídia tem apontado o reconhecimento da população gaúcha no que se refere à qualidade dos serviços prestados, mas a insatisfação dos

\footnotetext{
* Professora Adjunta da Escola de Administração da Universidade Federal do Rio Grande do Sul, doutora em Administração com ênfase em Organizações, mestre em Administração com ênfase em Recursos Humanos, psicóloga (PUC/RS).

** Juiz-corregedor doTribunal de Justiça do Estado do Rio Grande do Sul, secretárioexecutivo do Plano de Gestão pela Qualidade do Judiciário, mestrando em Administração do Poder Judiciário pela FGV.

*** Graduado em Administração na Escola de Administração da Universidade Federal do Rio Grande do Sul, bacharel em Ciências Jurídicas e Sociais (PUC/RS).

**** Especialista em Métodos Quantitativos (UFRGS), NRM Consultoria Estatística. ***** Mestre em Engenharia de Produção (UFRGS), NRM Consultoria Estatística.
} 
usuários em relação à celeridade de atuação do Poder Judiciário. Três questões parecem críticas neste contexto: a) até que ponto os esforços pessoais conseguirão suprir as demandas institucionais sem que haja um decréscimo na qualidade dos serviços prestados e/ou um burnout ${ }^{1}$ entre os magistrados e servidores? b) como cumprir a missão do Poder Judiciário, de "perante a sociedade, prestar a tutela jurisdicional, a todos e a cada um, indistintamente, conforme garantida na Constituição e nas leis, distribuindo justiça de modo útil e a tempo" (Rio Grande do Sul, 2005, p.5)? c) como alcançar a visão proposta de "tornar-se um Poder cuja grandeza seja representada por altos índices de satisfação da sociedade: cuja força seja legitimada pela competência e celeridade com que distribui justiça; cuja riqueza seja expressa pela simplicidade dos processos produtivos, pelo desapego a burocracias e por desperdícios nulos. Ou seja, uma Instituição moderna e eficiente no cumprimento do seu dever." (Rio Grande do Sul, 2005, p.5)? Estudos demonstram que a qualidade e a agilidade com que um produto ou serviço é oferecido ao mercado depende de inúmeros fatores, incluindo o ambiente externo (fornecedores, concorrentes, organismos de regulamentação, usuários dos serviços, economia, política, legislação, demografia, ecologia, cultura) e o ambiente interno (estrutura organizacional, clima e cultura organizacionais, valores, políticas e estratégias, tecnologias disponíveis, perfil do corpo funcional). O conhecimento, a compreensão e a capacidade de resposta às contingências geradas pela interação destes fatores é o que determina o desempenho organizacional (Lacombe; Heilborn, 2003).

Partindo desta visão sistêmica das organizações, pode-se supor que em paralelo às reformas administrativas, à simplificação e racionalização dos fluxos de trabalho, e à aplicação das modernas ferramentas da qualidade à análise organizacional, cumpre dimensionar o corpo funcional necessário para atender de forma adequada e rápida aos processos em tramitação, a partir de uma visão de curto-médio prazo. O aumento do número de magistrados e servidores poderia, numa visão de longo prazo, ser considerado como um paliativo, haja vista a impossibilidade de um aumento contínuo de recursos humanos, físicos e financeiros para atender às demandas processuais crescentes. No entanto, mesmo cientes desta limitação, entendese que o estudo da relação adequada entre o número de magistrados e de servidores e do número de processos compatíveis pode subsidiar ações futuras no sentido de se repensar qual a capacidade do Poder Judiciário de atendimento à sociedade e, eventualmente, priorizar as necessidades específicas de

\footnotetext{
1 "Em inglês, burnout significa apagar-se por falta de combustível; desgastar-se ou tornar-se inoperante como resultado de calor ou friç̧ão; exaustão, principalmente como resultado de excesso de trabalho." (RIFKIN, 1995, p.205).
} 
atendimento por este Poder, redirecionando as demais a partir da criação de mecanismos inovadores de atendimento jurisdicional, de mudanças na legislação, ou ainda da discussão de soluções integradas entre os três Poderes. Além disso, tal estudo pode identificar alternativas para um problema imediato e grave, permitindo um maior fôlego e serenidade para a tomada de decisões futuras.

Assim, ao iniciar-se o estudo que resultou no relatório análise da carga e da distribuição do trabalho no poder iudiciário do Estado do Rio Grande do Sul - magistrados e servidores da Justiça de Primeiro Grau (Costa; Michel; Michel, 2005), buscou-se analisar a existência de efetivas metodologias de levantamento da carga de trabalho de magistrados. Entretanto, optou-se pelo desenvolvimento de uma metodologia própria em função dos recursos disponíveis e das características específicas da instituição e da população-alvo. A metodologia desenvolvida será apresentada no item 4 deste ensaio.

A seguir são apresentadas algumas das metodologias pesquisadas quando da elaboração do desenho de pesquisa para o estudo do Tribunal de Justiça do Estado do Rio Grande do Sul.

\section{EXPERIÊNCIAS INTERNA- CIONAIS DE METODOLOGIAS DE MENSURAÇÃO DA CARGA DE TRABALHO DE MAGISTRADOS}

Desde a década passada foram realizadas várias pesquisas sobre a mensuração da carga de trabalho dos agentes do Judiciário e sobre a eficácia dos sistemas judiciais nacionais. Nesta seção são apresentadas metodologias e resultados de alguns estudos internacionais voltados para a mensuração do volume de trabalho dos magistrados.

\subsection{Estudos norte-americanos:} Assessing the need for judges and court support staff e the caserelated workload measures

\section{O National Center for State} Courts (NCSC), entidade fundada em 1971 com a atribuição de realizar estudos e propostas de reformas de âmbito administrativo aos tribunais estaduais norte-americanos, define, na sua página da internet, a avaliação de carga de trabalho (workload assessment) como o processo de conversão do número de casos em uma carga de trabalho, considerando-se o tempo dedicado na avaliação dos processos como representante da carga de trabalho (NCSC, 2006). A entidade sugere que a conversão do número de processos em carga de trabalho deve ser feita pelo Weighted Caseload Method, ${ }^{2}$ a seguir detalhado, que, na essência, consiste na divisão do tempo que o magistrado precisaria para apreciar os casos pelo tempo disponível para fazê-lo, consi-

2 O site do NCSC informa que realizou desde 1990 estudos para a implementação do Weighted Caseload nos seguintes estados: California, Colorado, Iowa, Maryland, Minnesota, New Hampshire, New Mexico e Oregon (NCSC, 2006). 
derando a variação de complexidade entre os tipos de processos. ${ }^{3}$

O Workload Assessment objetiva determinar os recursos necessários para que os tribunais atinjam com êxito os seus objetivos de desempenho. O método permite ao Judiciário não somente mensurar seu desempenho com a equipe atual, mas também estimar o que se pode alcançar com recursos adicionais. Tal determinação da carga de trabalho permite aos tribunais elaborar os seus pedidos de consolidação orçamentária de forma mais apropriada, de modo a possibilitar a contratação de magistrados e de servidores em números adequados para o atendimento da demanda. ${ }^{4}$
O estudo Assessing the need for iudges and court support staff, organizado no ano de 1996 pelo National Center for State Courts, apresenta e analisa várias metodologias usadas em diversos estados norteamericanos para avaliar a necessidade de aumentar, ou não, o número de magistrados e de servidores. O estudo sugere que a avaliação da necessidade de magistrados deve usar técnicas que sejam racionais (objetivas, coerentes e claras), críveis (aceita por magistrados, legisladores e pela sociedade) e práticas (as cortes locais devem oferecer os dados para que seja realizada a avaliação da carga de trabalho)(Flango; Ostrom, 1996). As técnicas sumariamente descritas

3 Do original: Weighted caseload is a method used to translate court cases into workload for judges and court staff. [...] Workload assessment is a process of converting caseloads into workload using time as a proxy for workload. It is based on the assumption that the more time it takes to process a case, the more work is involved. The method, in essence, simply divides the amount of judge time needed to hear all of the cases filed by the amount of time judges have available to hear cases. To account for the variation in complexity among different case types, specific case weights? the average amount of time needed to handle a particular case ? are developed. By weighting court cases, a more accurate assessment can be made of the amount of time required to process the caseload, i.e., caseload can be translated into workload (NCSC, 2006).

4 Do original: Workload assessments are intended to determine the resources necessary for courts to achieve their performance objectives. They enable courts not only to measure how well they are performing with their existing judges and court staff but also to estimate what could be achieved with additional resources. These performance improvements include better quality of the case processing as well as increases in the number of cases that could be processed. Objective methods and measures for determining appropriate judicial workloads enable courts to approach their legislatures with appropriate funding requests. Although empirical information alone will not guarantee favorable staffing decisions, it is unlikely that courts will obtain the judges and staff necessary to process cases without strong, empirically based documentation of need (NCSC, 2006). 
estão divididas em dois grandes grupos, os relacionados ao número de proces$\operatorname{sos}^{5}$ e os não-relacionados ao número de processos ${ }^{6}$ (Flango; Ostrom, 1996).

$\mathrm{O}$ estudo recomenda o Weighted Caseload Method (Método de Número de Casos Ponderado) como o melhor método para determinar a necessidade do número de magistrados, podendo ser utilizado em conjunto com a Delphi technique. O método Weighted Caseload consiste na realização das etapas a seguir descritas (Flango; Ostrom, 1996):

1. Selecionar uma amostra de processos, considerando alguns critérios: diversidade geográfica da localidade; tamanho do tribunal: tempo médio de apreciação dos processos; número de "quase magistrados" (que possuem denominações variadas, como árbitros, comissários, mestres); e infra-estrutura em informática.

2. Determinar o número de intervenções que cada tipo de processo demanda do magistrado.

3. Calcular o "tempo médio judicial" de cada ação acima identificada, com um estudo de tempo, no qual se solicita aos magistrados que registrem o tempo de início e fim de cada intervenção.

4. Determinar a frequêencia média de ocorrência de cada ação em cada tipo de processo, apurada conforme registros da movimentação processual no sistema de acompanhamento processual de cada estado, ou apurada de acordo com verificação em uma amostra de processos.

5. Criar o "peso da tarefa" (task weight) de cada tipo de processo, com a multiplicação do "tempo médio judicial" com a freqüência média de ocorrência de cada intervenção em cada tipo de processo.

6. Determinar o "peso de cada tipo de processo" (case weight), inicialmente com a soma de todos os "pesos de tarefa" identificados em cada tipo de processo, e depois com a sua multiplicação com o número de processos arquivados de cada tipo. O peso de cada tipo de processo representa o período de tempo que cada processo demanda de cada magistrado.

7. Determinar a quantidade de tempo disponível do magistrado para apreciar processos por ano, considerando que o magistrado não trabalha somente na apreciação de processos, pois atua também em atividades administrativas, eventos cívicos, educação pública, entre outras. A quantidade de tempo disponível por ano para apreciar processos é obtida pela multiplicação do número de dias de trabalho pelo número de horas para apreciação de processos de um dia que um magistrado dispõe.

8. Dividir a soma total do número de tempo exigido para apreciar antecipadamente o número de processos pelo tempo disponivel por magistrado para apreciar processos.

5 São descritas as metodologias por casos pendentes, casos arquivados, processos distribuídos, e tempo de apreciação por tipo de processo.

6 São descritas as metodologias por verificação da assistência judicial das localidades vizinhas, tamanho e crescimento da população, número de advogados e tempo de deslocamento do magistrado entre as cortes. 
Flango e Ostrom (1996) descrevem como vantagens do método Weighted Caseload a possibilidade de se considerar os diferentes tipos processuais e de mensurar a necessidade de magistrados para distritos judiciais de diferentes tamanhos. Mas o método apresenta algumas limitações e dificuldades para a sua implementação: a dificuldade de obter cooperação dos magistrados para apurar o "tempo judicial médio"; a dificuldade dos "pesos dos processos" manterem-se atualizados; a possibilidade dos pesos retratarem uma realidade de ineficiência, em vez de serem referenciais de índices de eficiência, gerando um "culto à ineficiência"; os pesos serem baseados em dados inexatos e inadequados; processos pendentes não serem considerados; as médias estaduais serem injustas com as pequenas comarcas; e o método apresentar como resultado uma "magistratura fracionada", ou seja, se, por ventura, o resultado do Weighted Caseload for de um magistrado e meio (Flango; Ostrom, 1996).

Conforme referido anteriormente, a aplicação do Weighted Caseload Method é compatível com a Delphi technique. A Delphi technique consiste na coleta da percepção de uma amostra de magistrados sobre o tempo despendido em cada intervenção de cada tipo de processo e no número de processos de cada tipo por eles apreciados. Posteriormente, calcula-se as médias das respostas de modo a determinar para cada ato e tipo de processo um tempo médio, usado como referencial para a estimativa do número de magistrados necessários pelo Weighted Caseload. A coleta da percepção dos magistrados nas intervenções processuais em vez da verificação do registro delas por parte dos mesmos (conforme sugerido na etapa $\mathrm{n}^{\circ} .3$ do Weighted (aseload) possibilita uma construção de "pesos processuais" com mais credibilidade, pois conta com uma maior participação de magistrados, além de ser mais econômica para o Judiciário (Flango; Ostrom, 1996).

Sobre a mensuração do número de magistrados para o volume de processos existentes proposta pelo estudo Assessing the need for judges and court support staff, algumas considerações importantes ali constantes devem ser expostas. A primeira é de que a metodologia utilizada para a verificação do número de magistrados não se aplica aos servidores, em razão da diferença da natureza das suas atividades (Flango; Ostrom, 1996). A segunda é de que não existe modelo estatístico que apresente resultados definitivos e incontroversos; e, por fim, que os dados obtidos devem ser interpretados considerando o contexto social, cultural e político do ambiente pesquisado (Flango; Ostrom, 1996).

No ano de 1993 a Conferência Judicial dos Estados Unidos (Judicial Conference), principal órgão de elaboração de políticas da justiça federal americana, aprovou o The CaseRelated Workload Measures (As Medidas de Carga de Trabalho Relacionadas com Processo), um sistema de medição dos tempos processuais. 
Este sistema teve como base um estudo realizado entre 1987 e 1993 , em que os magistrados registraram o tempo dedicado desde o início até o término em cada um dos processos integrantes do grupo de amostra (cerca de 8.100 processos em matéria de direito civil e cerca de 4.200 processos em matéria criminal). Os processos inseridos na amostra foram agrupados por tipo de ação (civil e criminal) e natureza de litígio. Para cada tipo foi atribuído um valor decorrente do cálculo da média obtida com base no número de minutos registrados pelos magistrados, salvaguardando-se uma margem de erropadrão. As médias apuradas e as margens de erro foram convertidas em valores relativos (denominados caseweights). Estes valores possuem caráter relativo uma vez que o estudo pretendeu descrever a quantidade média de tempo gasto pelos magistrados e não criar valores temporais a serem obrigatoriamente obedecidos pela magistratura de modo a condicionar a sua forma de trabalho. Com base naqueles valores foram criados limites de cargas de trabalho. Em um District Court entendeu-se que cada magistrado deveria trabalhar com um limite de 430 processos; e em uma Court of Appeal, geralmente constituído por um colegiado de três magistrados, entendeu-se que cada colegiado deveria trabalhar com 500 processos (Santos, 2005).

No ano de 2003 o sub-comitê de Estatísticas da Justiça (Subcommitee on Judicial Statistics) aprovou um projeto de reforma deste sistema, adaptando-o às novas realidades dos processos cíveis e criminais. $\mathrm{O}$ novo projeto não estabelece mais a medição do tempo despendido pelos magistrados, uma vez que a maioria das bases de dados registravam apenas o tempo dos magistrados na sala de audiências e desconsideravam o tempo gasto com outros atos processuais. Assim, propõese que o cálculo do tempo seja feito com base na opinião de treze grupos constituídos por magistrados com experiência através de painéis de discussão. Este novo sistema foi criado com base num método que considera os vários atos registrados ao longo da duração dos processos e incluí atos como julgamentos, inquirições de testemunhas e outro tipo de diligências; análise e pesquisa dos assuntos em litígio; e a realização de despachos (Santos, 2005). As alterações propostas resultarão no aumento dos case-weights e, consequientemente, em um aumento proporcional das cargas de trabalho por magistrado, que, por sua vez, será o fundamento para a formulação de recomendações para aumentar o número de magistrados (Santos, 2005).

\subsection{A experiência espanhola: os módulos de trabajo}

No ano de 1989 o Pleno do Consejo General del Poder Judicial (CGPJ), órgão constitucional com a competência de gestão administrativa do Poder Judiciário espanhol, aprovou a criação de módulos de trabajo para os órgãos judiciais com o objetivo de 
determinar a carga máxima de trabalho que um órgão judicial pode suportar, definindo o número ideal de processos por magistrado. Os módulos estabelecem as regras sobre a produtividade exigida para cada magistrado em relação ao número pré-estabelecido de processos que lhe serão distribuídos e em relação ao número de magistrados constante na Planta Judicial (Espanha, 2003).

Existem dois tipos de módulos de trabalho: os módulos de entrada y carga máxima, que representam a carga máxima de trabalho que razoavelmente um magistrado deve suportar em sua jornada ordinária de trabalho (estabelecidas em 1.760 horas por ano); e os módulos de salida, de resultado o dedicación, que têm como objetivo medir o grau de dedicação e resultados que deveriam ser alcançados pelos magistrados na jornada de trabalho estabelecida. O CGPJ pretende melhorar o sistema de avaliação do grau de dedicação dos magistrados através de outros fatores que não exclusivamente o número de sentenças proferidas (Espanha, 2003).

Os módulos de entrada y carga máxima têm como objetivo principal a determinação da Planta Judicial, que estabelece o número ideal de magistrados, de modo que quando o volume de processos iniciados ultrapassa o estabelecido no módulo, é um indicativo da necessidade de criação de um novo órgão jurisdicional ou de uma plaza (circunscrição territorial equivalente à uma comarca). Para a criação de novas plazas, deve ser considerado o registro do número anual de processos iniciados, e não a quantidade de processos acumulados, que devem ser apreciados de acordo com as ações decorrentes da análise da situação específica (Espanha, 2003).

A Planta Judicial estabelecida para o ano de 2000 e mantida em 2003 que indica a proporção de magistrados em relação à população e aos processos iniciados é a seguir exposta (Espanha, 2003, p. 44.797):

\section{Quadro 1 - Número de magistrados por habitante}

$\begin{array}{cc}\text { Número de habitantes } & \text { Número de magistrados na Planta } \\ \text { em 31/12/1998 } & \text { Judicial em 31/03/2000 }\end{array}$ Proporção

39.852 .651

3.917

1 para cada 10.174

Fonte: Consejo General del Poder .Iudicial, 2003.

\section{Quadro 2-Número de processos por magistrado por ano}

Número de processos novos em $31 / 12 / 1998$

\author{
Número de Magistrados na Planta \\ Judicial em $31 / 03 / 2000$
}

Proporçâo 1 para cada 1.493

Fonte: Consejo General del Poder .Judicial, 2003. 
Sobre o papel do módulo de entrada, o Acuerdo de 03 de dezembro de 2003, do Pleno do Consejo General del Poder Judicial, expõe que (Espanha, 2003, p. 44.797):

El módulo de entrada, que se propone, es consecuencia de esta proporción y realista en relación a la carga de trabajo que vienen soportando los órganos judiciales, de modo que no constituye el ideal, que solo se alcanzará cuando la evolución del crecimiento de la plantilla lo permita. En una proyección a futuro, cuando la planta de los distintos órganos iurisdiccionales alcance los niveles óptimos para hacer frente a los asuntos confiados al conocimiento de cada órgano, el tiempo de demora em la resolución de los asuntos cedería prioridad y se podría dar lugar a la inclusión de otros factores, entendiendo, siempre y en todo caso, que la resolución de los conflictos sometidos a conocimiento, en un tiempo razonable, es una de las principales exigencias de calidad.

Para a obtenção dos "níveis ótimos" desejados, a atualização dos módulos de entrada é prevista para ser realizada gradualmente, de modo a adequá-la às modificações que podem ocorrer na Planta Judicial no curto prazo, e também devem influenciar na defínição dos módulos de saída.

Sobre a utilidade dos módulos de trabalho, Boaventura de Souza Santos pondera que (2005, p. 56):

Um módulo de trabalho é um indice que apenas permite uma aproximação à actividade jurisdicional, não permitindo retirar conclusões sobre a realidade que se está a valorar. Para se proceder a uma análise desse tipo, devem ser tidas em conta outras circunstâncias, como a entrada de processos, a alocação dos magistrados, as licenças de maternidade, licenças para estudo e outras situações que têm incidencia no desempenho da actividade jurisdicional. Serve, também, para comparar a situação dos tribunais com competência na mesma área-territorial e com competências similares, detectando diferenças anormais na resolução dos litígios.

Várias foram as manifestações contrárias ao sistema de módulos, em especial as emanadas pela Asociacón Profesional de la Magistratura e a Asociacón Jueces para la Democracia, que, em suma, se manifestaram que o sistema de módulos ignora que a realidade do Judiciário espanhol é muito variada, em razão das variações de população, infra-estrutura, peculiaridade de cada processo, entre outros argumentos (Santos, 2005). No início do ano de 2006 a regulação do sistema de módulos estabelecida pelo CGPJ foi suspensa pelo Tribunal Supremo espanhol (Lázaro, 2006).

\subsection{Os estudos do Ministério da Justiça de Portugal}

Conforme a publicação Estudo sobre Contingentação Processual, visando a definição de indicadores fiáveis sobre o volume de serviço adequado para cada juiz dos 
tribunais judiciais, de julho de 2002 , o Hay Group S.A. de Lisboa, em consultoria solicitada pelo Gabinete de Auditoria e Modernização do Ministério da Justiça de Portugal, propôs-se ao seguinte (Hay Group, 2002, p. 5):

- Desenvolver um trabalho de campo, procedendo ao levantamento do estado actual dos tribunais no foro da iurisdição penal (Diagnóstico do Estado Actual dos Tribunais), com base na selecção de amostra representativa do universo dos tribunais de jurisdição criminal, que permita aferir a pertinência dos factores críticos das variáveis previamente identificadas (Variáveis de Capacidade, Técnicas, Organizativas e de Experiência), bem como a acuidade da fórmula de contingentação de processos;

- Definir, propor e validar a fórmula de contingentação de processos, que permita fixar de modo orientador, um valor de carga máxima de trabalho adequado à tipologia de juizes objecto de estudo;

- Estabelecer critérios, procedimentos e metodologia de referência, com vista ao alargamento do estudo ao universo dos restantes tribunais;

- Criar os alicerces de base cientifica, necessários ao desenvolvimento de uma melhor politica de justiça em Portugal.

Para atingir tais objetivos utilizou a seguinte metodologia (Hay Group, 2002, p. 6):

O trabalho de campo desenvolveu-se em duas vertentes distintas mas complementares: se por um lado seria necessário dispor de informação de cariz quantitativo que, juntamente com a informação estatística, pudesse alimentar o modelo conceptual da fórmula de contingentação (diagnóstico quantitativo), por outro importava aferir junto de um painel de peritos (Magistrados indicados pelo Conselho Superior de Magistratura) informação de cariz qualitativo, por forma a garantir não só a correcta adequação do conteúdo do questionário a aplicar, como um maior aprofundamento das variáveis relacionadas com a componente humana, processual e organizacional.

Considerando a relativa homogeneidade dos indicadores operativos (complexidade do mix de processos - Variável Técnica) a analisar no âmbito da jurisdição penal, importava proceder à sua sintese, ou seja, agregar os processos que exigem intervenção do iuiz de jurisdição penal, por forma a isolar tais processos em categorias de acordo com os critérios de complexidade/consumo de tempo, pretendendo-se alcançar um ranking de processos-tipo, de acordo com a maior ou menor exigência em termos de complexidade versus consumo de tempo.

Para a mensuração da carga de trabalho adequada aos magistrados da área criminal, o Hay Group aplicou questionário estruturado para 74 magistrados, realizou 16 entrevistas individuais com magistrados préselecionados e realizou sessões de trabalho em conjunto com o Conselho Superior da Magistratura. Conforme observa Boaventura de Souza Santos (2005), não foi realizada qualquer análise dos registros do trabalho efetivamente desenvolvido pelos magistrados nos processos. 
O modelo conceitual para identificar o volume de trabalho dos magistrados judiciais foi estabelecido em função de quatro variáveis: $1^{\circ}$ ) Variável Técnica, compreendendo os indicadores relativos à complexidade de processos; $2^{\circ}$ ) Variável Capacidade, compreendendo os indicadores relativos à capacidade instalada; $3^{\circ}$ ) Variável Organizacional, compreendendo os indicadores relativos aos tribunais; $4^{\circ}$ ) Variável Humana, compreendendo os indicadores relativos aos magistrados.

As diferentes medições e ponderações atribuídas a cada variável resultaram no tempo que um Magistrado ("Juiz com boa performance") deveria necessariamente dedicar a um tipo de processo. calculada tendo em consideração a exigência de tempo destinado em cada tipo de processo e pelo mix de processos de cada magistrado. A classificação dos processos criminais em função da sua complexidade teve por base os resultados das entrevistas efetuadas com os magistrados, bem como das sessões de trabalho conduzidas junto do Conselho Superior de Magistratura. Também foi considerado o tempo dedicado pelos magistrados às demais atividades inerentes ao exercício da magistratura: 1) estudo de processos; 2) despachos; 3) julgamentos e outras diligências; 4) elaboração de sentenças; 5) reuniões e deliberações coletivas; 6 ) atividade de gestão administrativa da secretaria; 7) deslocamentos em serviço.

\begin{tabular}{|c|c|c|c|}
\hline \multicolumn{4}{|l|}{$\begin{array}{l}\text { Contingentaça de } \\
\text { Processos } \\
\text { (volume máximo } \\
\text { razoável) } \\
\end{array}$} \\
\hline 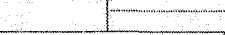 & $T$ & 1 & 7 \\
\hline Variável Capacidade & Variável Técnica & Variável & Variảvel Humana \\
\hline $\begin{array}{l}\text { Capacidade instalada } \\
\text { horas de trabalho } \\
\text { disponíveis }\end{array}$ & $\begin{array}{l}\text { Complexidade } \\
m i x \text { processos }\end{array}$ & $\begin{array}{l}\text { Organizacional } \\
\text { Coeficiente organi- } \\
\text { zacional tribunal }\end{array}$ & $\begin{array}{c}\text { Coeficiente } \\
\text { experiência } \\
\text { juiz }\end{array}$ \\
\hline
\end{tabular}

Fonte: HAY GROUP, 2002, p. 14

Como variável capacidade foi utilizado o indicador "número de horas de trabalho disponíveis" (rácio_horas), definido como a discrepância do número de horas semanais efetivamente trabalhadas pelo magistrado em relação à carga horária semanal de 40 horas estabelecida como padrão (equivalente a 8 horas de trabalho por dia).

A variável técnica, que considera a complexidade dos processos criminais, foi medida em pontos e
Para a avaliação da complexidade dos processos, o Hay Group utilizouabordagem idêntica a modelos de contingentação já utilizados em estudos anteriores ao considerar três etapas metodológicas: classificação dos processos de acordo com a respectiva complexidade; identificação dos tempos médios (em horas) dedicados em cada processo, com atribuição de uma escala, em termos de pontos, para cada processo, de modo a obter a respectiva ponderação em função da complexidade; e apuração do volume de pontos realmente trabalhados por cada magistrado (Hay Group, 2002). 
A variável organizacional compreendeu os indicadores: 1) número de funcionários; 2) número de salas de audiência; 3) existência de gabinete próprio; 4) disponibilidade de meios de gravação e reprodução; 5) disponibilidade de meios de vídeoconferência. A variável humana foi trabalhada com os indicadores
2002). A constante na equação é resultado de uma regressão linear da variável capacidade (rácio_horas) em relação à variável técnica (pontos) (Hay Group, 2002).

A seguir, um quadro que resume os resultados encontrados nos estudos do Hay Group. experiência do Magistrado, sua antiguidade no tribunal e sua idade. Aidentificação das correlações estatísticas mais relevantes da variá-

\section{Quadro 3 - Resultados parciais do estudo do Hay Group} Tipo de tribunal

$\mathrm{N}^{\circ}$ de processos por magistrado (aplicando a fórmula de contingentação

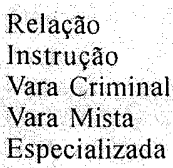

\section{Goner}

Fonte: Hay Group, Estudo sobre Contingenlação Processual, visando a definição de indicadores fiáveis sobre o volume de serviço adequado para cada juiz dos tribunais judiciass, 2002, p. 64. vel organizacio-

nal e da variável humana possibilitou a elaboração do Coeficiente Organizacional.

Considerando as variáveis acima, é proposta a fórmula final de Contingentação Processual, que é dada pela equação Pontos $=$ Constante $*$ Rácio Horas* Coeficiente Organizacional. A fórmula significa que o total de pontos a serem realizados anualmente por um magistrado, considerada a complexidade de cada tipo de processo criminal, depende das horas trabalhadas ponderadas por um coeficiente de produtividade pessoal e organizacional (Hay Group,
No ano de 2005, o Observatório Permanente da Justiça Portuguesa, vinculado ao Centro de Estudos Sociais da Faculdade de Economia da Universidade de Coimbra, realizou, também por solicitação do Ministério da Justiça de Portugal, o estudo Os actos e os tempos dos juízes: contributos para a construção de indicadores da distribuição processual nos juizos cíveis, com o objetivo de "construção de indicadores de distribuição processual e de avaliação e de projecção do volume de trabalho dos juízes dos juízos cíveis ${ }^{7}$ que

7 Os juízos cíveis foram divididos em oito tipos: $\mathrm{J} 1$ - Juízos cíveis com competência para toda a jurisdição cível; J2 - Juízos cíveis com competência para toda a jurisdição cível, com excepção da competência dos tribunais de comércio; J3 - Juízos cíveis com competência para toda a jurisdição cível, com excepção da competência dos tribunais de família e menores; J4 - Juízos cíveis com competência para toda a jurisdição cível, com excepção da competência dos tribunais de família e menores e dos tribunais de comércio; J5 - Juízos cíveis com competência para toda a jurisdição cível, com excepção da 
possam vir a contribuir para uma distribuição de processos e de recursos humanos de acordo com critérios mais transparentes" (Santos, 2005, p. IX).

Em razão da peculiaridade do tema em estudo, complexa foi a metodologia utilizada (Santos, 2005, p. 508):

Este projecto de investigação conjuga diferentes metodologias, algumas, do nosso conhecimento, nunca utilizadas em estudos similares; o que, por um lado, fez aumentar o grau de complexidade da investigação e, por outro, a necessidade de aplicação de vários modelos e de uma interacção constante entre os dados e as componentes analiticas.

A metodologia utilizada neste projeto socorreu-se de uma multiplicidade de métodos quantitativos e qualitativos. Compreendeu a recolha e análise de vários estudos, nacionais e estrangeiros, sobre a avaliação do volume de trabalho, o desempenho dos juizes e dos tribunais e a qualidade da iustiça; a recolha e tratamento de legislação relativa à organização judiciária portuguesa, ao direito processual aplicável aos processos judiciais da competência dos juízos civeis e aos estatutos dos magistrados; a realização de entrevistas exploratórias com informadores privilegiados; a realização de entrevistas semiestru- turadas com juizes em exercicio de funções nos juízos civeis; a realização de dois painéis de discussão com a intervenção de magistrados judiciais e de funcionários judiciais; a análise das estatísticas oficiais da justiça do GPLP do Ministério da Justiça sobre o movimento e caracterização da iustiça civel e, em especial, sobre o movimento processual dos juizos civeis e sobre a caracterização dos processos findos nesses juizos; a observação do quotidiano dos juizes e funcionários em dois tribunais; $e$ a recolha e tratamento de dados quantitativos de uma amostra de 972 processos em sete juizos civeis.

Para que fossem definidos indicadores de distribuição processual, de avaliação e de projeção do volume de trabalho dos magistrados dos juízos cíveis, de modo a ser designado o "tempo esperado do juiz por processo de determinada categoria de objecto de acção" (Santos, 2005, p. 20), duas informações precisaram ser coletadas: o tempo médio que o magistrado no juízo cível despende, em regra, para a prática das intervenções processuais da sua competência; e quais as intervenções um magistrado realiza nos processos de competência do juízo cível.

competência das varas cíveis; J6 - Juízos cíveis com competência para toda a jurisdição cível, com excepção da competência dos tribunais de família e menores e da competência das varas cíveis; $\mathbf{J} 7$ - Juízos cíveis com competência para toda a jurisdição cível, com excepção da competência dos tribunais de família e menores, dos tribunais de comércio e da competência das varas cíveis; e J8 - Juízos cíveis com competência para toda a jurisdição cível, com excepção da competência dos tribunais de família e menores, dos tribunais de comércio, da competência das varas cíveis, dos juízos de pequena instância cível e dos juízos de execução (Santos, 2005, p. 515). 
A identificação do tempo médio despendido pelo magistrado foi obtida através de entrevistas semi-estruturadas com dezenove magistrados, de modo que o tempo considerado no estudo não foi o tempo real de cada intervenção, mas sim o tempo percebido pelos respondentes (Santos, 2005). Para que tal identificação ocorresse, foi executada uma coleta de dados em três etapas. Na primeira ocorreu a identificação do volume de trabalho semanal dos juízes e da forma como ele está distribuído pelas diferentes intervenções processuais de sua competência, agregadas em sete categorias ${ }^{8}$. Aos entrevistados foi solicitado que, considerando o seu método de trabalho e número médio semanal de horas de trabalho, indicassem o número médio de horas de trabalho despendido, por semana, na execução das intervenções de cada uma das categorias acima referidas.

A segunda etapa consistiu na manifestação dos entrevistados do tempo médio despendido na prática de 37 categorias de intervenções ${ }^{9}$ selecionadas no conjunto do seu volume de

8 1) Despachos e diligências relativos à acção executiva (todo o trabalho do juiz que esteja relacionado com o processo executivo); 2) Despachos e diligências relativos ao antigo processo de recuperação de empresas e falência ou ao novo processo de insolvência (todo o trabalho do juiz que esteja relacionado com estes processos); 3) Despachos escritos de mero expediente ou de simples apreciação (com duração média até $30 \mathrm{~min}$ ); 4) Despachos saneadores; 5) Outros despachos de fundo (sentenças que demorem mais de $30 \mathrm{~min}$ ); 6) Audiências de produção de prova (julgamentos, outras audiências ou inquirições); 7) Outros actos públicos (juramento de peritos) (Santos, 2005, p. 316).

9 1) Despachos de indeferimento da petição inicial: 2) Despachos de recebimento da petição inicial /citações / notificações (equivalentes à citação); 3) Despachos de admissão / não admissão de articulados / reconvenção / intervenção de terceiros; 4) Despachos a conhecer da incompetência / competência do tribunal, sem ser no âmbito do despacho saneador; 5) Despachos de aperfeiçoamento; 6) Tentativas de conciliação; 7) Audiências preliminares; 8) Despacho saneador-tabelar (ex: acção não contestada, saneador com dispensa de base instrutória); 9) Despachos saneador-sentença e despachos a conhecer de excepções, nulidades, incompetências, ilegitimidades e outras questões que invalidam o prosseguimento da lide e o conhecimento do mérito da causa; 10) Despachos saneador com factos assentes e base Instrutória; 11) Despacho a decidir a reclamação relativa à selecção dos factos assentes e base Instrutória; 12) Despachos a ordenar a produção de prova; 13) Despachos a designar data para a realização de diligências / julgamentos a efectuar pelo juiz; 14) Audiências de julgamento; 15) Despachos de resposta à matéria de facto, após julgamento; 16) Sentenças homologatórias de acordos / transacções / desistências do pedido e da instância; 17) Sentenças sem prévia produção de prova (ex. processos especiais de jurisdição voluntária); 18) Sentenças após produção de prova, sem julgamento (ex. procedimentos cautelares); 19) Sentenças após julgamento; 20) Sentenças proferidas pelo juiz no âmbito de recursos de decisões proferidas por outras entidades; 21) Despachos que decidem sobre requerimentos de esclarecimento / reforma 
trabalho e qual o seu peso relativo. $O$ peso relativo de cada intervenção foi obtido com a resposta de qual a percentagem das intervenções mais demoradas, das menos demoradas, e das de duração intermédia. Com isso foi conhecido se no volume das intervenções dos 37 tipos predominavam as mais ou menos demoradas ou as de duração intermediária.

A terceira etapa tinha como objetivo conhecer o peso relativo de cada um dos 37 tipos de intervenções no volume de trabalho dos magistrados. As respostas permitiram conhecer como os magistrados avaliaram a distribuição do seu tempo de trabalho, isto é, qual a sua avaliação das intervenções mais freqüentemente praticadas, e confrontá-la com as intervenções que efetivamente praticam nos processos (informação essa obtida através da amostra de processos, a seguir descrita). Aos entrevistados foi solicitado que ordenassem, do mais freqüente para o menos freqüente, as 20 intervenções mais freqüentemente praticadas no último mês. Em seguida, para cada uma destas 20 intervenções, foi solicitado que indicassem qual o peso relativo no seu volume semanal de trabalho; o peso relativo no número de intervenções praticadas, e, se possível, o número médio absoluto de intervenções praticadas. Este tempo médio foi o usado para aplicar em cada uma das intervenções identificadas em cada um dos processos da amostra para que fosse determinado o "tempo esperado do juiz por processo de determinada categoria de objecto de acção" (Santos, 2005, p. 20).

A relação das intervenções realmente praticadas nos processos de com-

de sentenças; 22) Despachos a reparar ou sustentar o agravo/suprir nulidades; 23) Outros despachos relativos à tramitação de recursos de decisões do juiz; 24) Vistos em correição; 25) Diligências em que o juiz toma juramento/compromisso de honra a intervenientes processuais; 26) Audiências de produção de prova presididas pelo juiz sem ser em julgamento; 27) Diligências presididas pelo juiz relativas à venda/adjudicação de bens; 28) Conferências com os pais, no âmbito da regulação do poder paternal; 29) Conferência de interessados, em processo de inventário/divisão de coisa comum/separação de bens; 30) Despacho determinativo da forma à partilha; 31) Decisão relativa a incidentes em processo de inventário; 32 ) Assembléias de credores (processos de recuperação empresas/ falência/ insolvência); 33) Outros despachos de mero expediente; 34) Despachos e diligências relativos à acção executiva antiga (todo o trabalho do juiz que esteja relacionado com o processo executivo); 35) Despachos e diligências relativos à nova acção executiva (todo o trabalho do juiz que esteja relacionado com o processo executivo); 36) Despachos e diligências relativos ao antigo processo de recuperação de empresas e falência (todo o trabalho do juiz que esteja relacionado com estes processos); 37) Despachos e diligências relativos ao novo processo de insolvência (todo o trabalho do juiz que esteja relacionado com estes processos) (Santos, 2005, p. 318 ). 
petência dos juízos cíveis foi obtida pela consulta e da análise de uma amostra estratificada de 972 processos, elaborada de forma proporcional pelas 87 diferentes naturezas de litígio, de acordo com a classificação do Gabinete de Política Legislativa e Planejamento do Ministério da Justiça, agregadas em 15 categorias: 1) divórcio; 2) inventário; 3) outras acções sobre o estado das pessoas, família e sucessões; 4) dívidas; 5) contrato de arrendamento; 6) outros actos, contratos e outras obrigações; 7) direito de propriedade e direitos reais; 8) tutelares cíveis; 9) recuperação de empresas; 10) registos e notariado; 11 ) procedimentos cautelares; 12) embargos de executado; 13) reclamação de créditos; 14) outros processos; 15) acções executivas (Santos, 2005).

Para os processos da amostra, foram registradas as intervenções praticadas, a data da sua realização e quem as fez, se foi magistrado, servidor judicial, membro do Ministério Público ou uma das partes. A análise dos processos da amostra possibilitou o detalhamento, de cada processo, da natureza do litígio e a sua forma; da duração das diferentes fases; dos intervenientes processuais; das intervenções praticadas; da sua freqüência; da distribuição cronológica; e o tempo que cada interveniente teve o processo ao seu dispor para realizar a sua intervenção.

Portanto, a obtenção do indicador "tempo esperado do magistrado por processo", em cada uma das 15 cate- gorias de litígio acima referidas, decorreu da interrelação da média de minutos despendida pelos magistrados em cada tipo de intervenção identificada com a duração média da categoria de processo, considerando o peso relativo das diversas naturezas de litígio dentro de cada uma das 15 categorias. Para cada categoria foi apresentado um quadro com a duração média ponderada dos processos da categoria antes e depois da sentença, e o tempo esperado do magistrado por processo da categoria antes e depois da sentença.

Com esta metodologia foi possível a realização de projeções do volume de trabalho (Santos, 2005, p. 471):

As metodologias desenvolvidas no nosso estudo permitiram-nos construir um indicador que designamos de "tempo esperado do juiz no processo" para cada uma das 15 categorias de naturezas de litígio identificadas nos capitulos precedentes. É possivel, conhecendo os processos entrados e pendentes num dado juizo, ter, através daquele indicador, uma estimativa do volume de trabalho dos juizes e avaliar em que medida se espera que esse volume de trabalho já tenha ultrapassado ou não o seu tempo de trabalho disponivel ou se espera que o venha a ultrapassar, levando a que o juiz entre numa situação de sobrecarga e conseqüente acumulação de volume de trabalho.

Os valores encontrados e esperados para a duração das categorias de processos acima expostas são os seguintes: 


\section{Quadro 4-Resultados parciais do estudo do OPJ - Comparação das 15 naturezas de litígio, ordenadas por minutos/mês de tempo esperado do juiz}

Objeto de litígio por
categoria agregada
Recuperação de empresas e
falências
Procedimentos cautelares
Registros e notariado
Divorcio
Outros atos, contratos e
obrigaçôes
Outras açóes sobre estado das
pessoas, familias e sucessões
Embargos de executado
Ações tutelares civeis
Contratos de arrendamento
Inventários
Direito de propriedade e
direitos reais
Dividas
Outras
Reclamação de créditos
Executivas

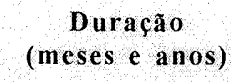

3 anos e 9 meses e meio

10 meses e meio

1 ano e 2 meses e meio

1 ano e 7 meses e meio

2 anos e 10 meses

2 anos e 3 meses

2 anos e 6 meses

1 ano e 7 meses e meio

1 ano e 8 meses

3 anos e 7 meses

3 anos e 1 mês

1 ano e 2 meses e melo

1 ano e 6 meses

1 ano e 5 meses

2 anos e 3 meses

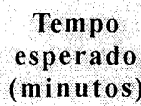

$1.062,87$

217,22

237,81

308,46

393,64

30506

331,98

215,02

212,13

446,33

361,92

13028

157,47

105,01

120,27

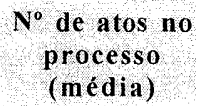

Fonte: SANTOS, Boaventura de Sousa. Os actos e os tempos dos juizes: contributos para a construçäo de indicadores da distribuçăo processual nos juzzos civeess, 2005, p. 465

E sobre as conclusões do estudo, Boaventura de Souza Santos pondera (2005, p. 533):

O que construimos são apenas indicadores, valores de referência, que nos permitem fazer dois tipos de estimativas. A primeira é saber, quando determinado processo entra num juizo civel, qual o trabalho, quer em média de actos, quer em tempo, que se estima que o juiz vá despender com ele e durante quanto tempo (indicadores que, do nosso conhecimento, até agora em nenhum ouiro estudo foram alcançados). Estes indicadores podem ser usados para criar critérios mais objetivos e mais transparentes de distribuição de processos, quer internamen- te no tribunal, pelos vários juizes, quer mesmo, entre tribunais. É possivel, a partir deles, conceber uma aplicação informática que vá contabilizando o tempo esperado do juiz, sempre que um determinado processo lhe é distribuido, podendo incorporar, nessa aplicação, sistemas de alerta que assinalarão uma situação de excesso de trabalho, sempre que o volume de trabalho estimado ultrapasse o tempo de trabalho disponivel. Logo que sinalizada a situação, ela deveria levar à sua avaliação e, uma vez comprovada, à intervenção, sobre ela.

Os indicadores apresentados podem, também, como demonstramos nos exercicios, servir para estimar o volume de trabalho, num determinado 
momento, do juiz de um juízo civel e compará-lo com o tempo de trabalho disponivel, permitindo, a partir deles, saber se o juiz está, ou não, em sobrecarga e distinguir situações em que estaremos perante problemas sistêmicos de situações em que estaremos perante problemas de desempenho. Mas, a avaliação que, a partir daquela estimativa, se faça deve sempre ter em conta o impacto de outros fatores, designadamente dos fat!res acima referidos, que só podem ser verificados no caso concreto em avaliação.

Como é possível observar, as diferentes experiências internacionais na busca por indicadores de carga de trabalho de magistrados, embora apresentem objetivos comuns, diferem em aspectos metodológicos. A seguir abordamos como os órgãos superiores do Judiciário brasileiro vêm desenvolvendo esforços no sentido de medir a carga de trabalho da Justiça, sendo em seguida apresentada a metodologia aplicada no estudo do Tribunal de Justiça do Estado do Rio Grande do Sul e, por fim, serão feitas considerações acerca dos diferentes métodos de pesquisa empregados.

\section{O ESTUDO DO SUPREMO TRIBUNAL FEDERAL: UMA EXPERIÊNCIA BRASILEIRA DE MENSURAÇÃO DA CARGA DE TRABALHO DOS MAGISTRADOS}

Em maio de 2005 foi organizado pelo Supremo Tribunal Federal (STF) o seminário A Justiça em Números Indicadores Estatísticos do Poder Judiciário Brasileiro, que apresentou relatórios estatísticos consolidados sobre as Justiças Comum, Federal e TrabaIhista relativos ao ano de 2003, além de indicadores do STF, Superior Tribunal de Justiça (STJ) e Tribunal Superior do Trabalho (TST) (Supremo Tribunal Federal, 2005). Dentre outros indicadores, foi apresentada uma fórmula de cálculo da carga de trabalho para as entrâncias da maioria dos âmbitos do Judiciário nacional. ${ }^{10} \mathrm{~A}$ fórmula mantinha as mesmas variáveis para todos os níveis analisados, exibindo variação no período e no tipo de processos considerados em algumas variáveis.

O Seminário apresentou a carga de trabalho de cada âmbito do Judiciário e em cada Estado, e estabeleceu uma média geral para cada Justiça analisada.

No início de 2006, o Conselho Nacional de Justiça (CNJ) apresentou a segunda edição do estudo $A$ Justiça em Números com os indicadores estatísticos do Poder Judiciário referentes ao ano de 2004, tendo analisado os mesmos âmbitos do estudo precedente e considerado variáveis diversas para estruturar a fórmula para o cálculo da carga de trabalho. Nesta edição, o estudo não considerou o número de processos sentenciados que estão em fase

10 Justiça Federal de $1^{\circ}$ e $2^{\circ}$ Grau; Juizado Especial Federal; Justiça do Trabalho de $1^{\circ}$ e $2^{\circ}$ Grau; Justiça Estadual de $1^{\circ}$ e $2^{\circ}$ Grau; e Juizados Especiais. 
de execução de sentença (Conselho Nacional da Justiça, 2006).

Em termos gerais, a fórmula de cálculo da carga de trabalho considerava a seguinte estrutura:

$$
\mathbf{K}=\frac{\mathrm{CN}+\mathrm{Cpj}+\mathrm{Cex}}{\mathrm{Mag}}
$$

Na qual:

$\mathrm{K}=$ Carga de trabalho

$\mathrm{CN}=$ Casos novos

$\mathrm{Cpj}=$ Casos pendentes de julgamento

$\mathrm{Cex}=$ Processos sentenciados, em execução ${ }^{11}$

Mag = Número de magistrados do âmbito de análise

Os resultados da aplicação desta fórmula são apresentados no quadro a seguir.

imprecisões metodológicas e falhas na análise e interpretação estatística, atacadas pelo doutor em Direito do Trabalho pela PUC/SP João José Sady como "manipulação estatística por métodos reducionistas". Tais imprecisões não levariam em conta a "evolução irracional e a distribuição desigual de recursos" (Sady, 2005).

Solange Salgado, presidente da Ajufer - Associação dos Juízes Federais da $1{ }^{\text {a }}$ Região, também não poupou críticas à metodologia empregada pelo STF: "a definição dos métodos de pesquisa é que garantirá o seu resultado positivo. A decisão da inclusão de situações peculiares na essência e no resultado, bem como a adoção de dados comparativos provenientes de realidades diversas,

Quadro 5-Resultados do cálculo da carga de trabalho por magistrado em diferentes níveis do Judiciário brasileiro realizado pelo STF e pelo CNJ - resultados das médias nacionais por nível

\section{Nivel da Justiça Analisado}

Supremo Tribunal Federal

Superior Tribunal de Justiça

Tribunal Superior do Trabalho

Justiça Federal do $2^{\circ}$ grau

Justiça Federal do $1^{\circ}$ grau

Justiça Federal - Juizados Especiais

Justiça do Trabalho de $2^{\circ}$ grau

Justiça do Trabalho de $1^{\circ}$ grau

Justiça do Trabalho de $1^{\circ}$ grau (fase de conhecimento)

Justiça do Trabalho de $1^{\circ}$ grau (fase de execução)

Justiça Estadual de $2^{\circ}$ grau

Justiça Estadual de $1^{\circ}$ grau

Justiça Estadual - Juizados Especiais
Ano de realização do estudo

A Justica em Números 2003 2004

23996

9.547

19.562

10.070

6.505

28.855

1.300

1.898

1306,87

3400,79

$6.398,13$ geraram, como não poderia deixar de ser, um resultado equivocado, muito aquém das necessidades dos utilizadores da pesquisa" (Salgado, 2005). Entre os principais equívocos apontados pela juíza está a forma como foi calculada a taxa de congestionamento, ${ }^{11}$ a eleição de um único ano como método para a pesquisa

11 Número de sentenças proferidas X casos novos, pendentes e processos em execução. 
e o cálculo de apuração do custo do judiciário.

"As execuções fiscais terminam se eternizando na Justiça", diz o presidente da AJUFE, uma vez que o cumprimento da condenação não depende da ação do juiz. Logo, as ações de execução fiscal não deveriam entrar no cômputo da pesquisa e muito menos compor índices de congestionamento. Segundo um levantamento realizado pelo TJ de São Paulo, das mais de 13 milhões de ações que ainda não foram concluídas, cerca de 7 milhões são de execução fiscal (Nanci, 2005).

Uma das principais informações trazidas à luz pela pesquisa do STF é a de que o Brasil tem um número médio de 7,7 juízes para cada 100.000 habitantes, mais do que a média internacional e um número de servidores que atinge mais do que o dobro da média internacional, o que poderia induzir à conclusão de que há magistrados e servidores em excesso, o que não necessariamente ocorre. "Um bom advogado pode usar até 120 recursos para protelar a sentença $[\ldots]$ é até natural que a gente precise de mais funcionários que os outros países", afirmou o jurista Dalmo Dallari, de São Paulo (Oltramari, 2005).

"Um dos indicadores que chamaram mais a atenção [na pesquisa do STF] foi a alta taxa de congestionamento: $84 \%$ na Justiça Federal. O número revela que de 100 processos que entraram em 2003, somados aos remanescentes de 2002, apenas 16 foram solucionados" - afirma-se em matéria publicada no sítio Canal Justiça (2004). Na mesma matéria, o Ministro Jobim se defende afirmando que estes resultados não são provocados por inoperância, mas por "um conjunto de situações".

O número médio de juízes para cada 100 mil habitantes (um dos indicadores utilizados pelo STF) é determinante da celeridade da Justiça? Muitos especialistas consideram que não, dadas as peculiaridades da estrutura dos sistemas judiciais de cada país e as características específicas dos processos. "Também não se deve alimentar a idéia, levantada pelo estudo [do STF], de que o Judiciário custa muito caro aos cofres públicos, "como se um serviço essencial pudesse ser avaliado através de valores" - afirmou o presidente da Anamatra - Associação Nacional dos Magistrados do Trabalho, Grijalbo Fernandes Coutinho (Nanci, 2005).

Uma das críticas mais severas partiu do presidente do STJ, Ministro Edson Vidigal, e do Ministro César Rocha, que afirmaram "não saber aonde se quer chegar com a pesquisa" (Cordeiro, 2005).

Apesar das críticas, a pesquisa do STF tem o mérito indubitável de tentar trazer à tona dados e indicadores que possibilitem à administração judiciária trabalhar de forma mais objetiva e precisa em suas análises, decisões e planejamento.

\section{UMA EXPERIÊNCIA LOCAL DE DESENVOLVIMENTO E APLICAÇÃO DE UMA METODOLOGIA DE MENSURAÇÃO DA CARGA DE TRABALHO DE MAGISTRADOS:}




\section{O ESTUDO DO TRIBUNAL DE JUSTIÇA DO ESTADO DO RIO GRANDE DO SUL}

O estudo Análise da Carga e da Distribuição de Trabalho no Poder Judiciário do Estado do Rio Grande do Sul: Magistrados e Servidores da Justiça de Primeiro Grau foi realizado atendendo a uma solicitação da Corregedoria-Geral da Justiça e do Plano de Gestão pela Qualidade no Judiciário.

O objetivo geral da pesquisa foi o levantamento e análise da carga e distribuição de trabalho no Poder Judiciário do Estado - Justiça de Primeiro Grau. Os objetivos específicos foram: identificar os tipos de processos nos quais os magistrados e os servidores de primeiro grau atuam; estabelecer indicadores da carga de trabalho nas atividades que exigem intervenções diretas nos processos judiciais, nas administrativas, de representação e de aperfeiçoamento, a partir da análise do número médio de horas semanais utilizadas nestas intervenções; estabelecer indicadores do número de processos recebidos e atendidos mensalmente pelos magistrados e pelos servidores; estabelecer indicadores a respeito do ambiente físico no qual os magistrados e os servidores atuam; e identificar as percepções acerca da carga de trabalho.

$\mathrm{Na}$ etapa de planejamento da pesquisa, as metodologias empregadas em outros países e mesmo no Judiciário Federal foram analisadas a fim de que se verificasse a aplicabilidade das mesmas aos objetivos da pesquisa do TJ-RS.
De imediato foram descartados os desenhos de pesquisa que previam a utilização de amostras estratificadas, haja vista ser intenção do Tribunal traçar um mapa geral da justiça gaúcha. A grande heterogeneidade da populaçãoalvo exigiria a estratificação em grupos muito pequenos e não representativos da população geral, o que causaria problemas na generalização dos achados e na própria operacionalização da pesquisa de campo, exigindo recursos indisponíveis no momento. Num segundo momento, foram descartadas as metodologias qualitativas devido à necessidade de quantificação da carga de trabalho e de sua expressão em números que apoiassem o dimensionamento do quadro de magistrados e o planejamento de políticas de distribuição de processos. O registro pelos próprios magistrados, ou por grupos de pesquisadores, dos tempos envolvidos nos atos processuais, acabou sendo cogitado como método complementar, possível de aplicação em um segundo estudo, igualmente devido aos recursos envolvidos e à disponibilidade demandada dos magistrados. Finalmente, optou-se pelo método abaixo descrito considerandose experiências bem sucedidas em ambientes diversos e por ser um método consagrado na Administração.

A seguir, o detalhamento da metodologia empregada.

\subsection{População alvo}

Considerando as características dos diversos segmentos do Poder Judiciário, 
a pesquisa foi planejada no sentido de obter informações junto a todos os magistrados e servidores em atuação no Poder Judiciário do Rio Grande do Sul.

Com tal definição foram incluídos na amostra magistrados e servidores que atuavam em todos os tipos de processos da Justiça de primeiro grau, nas entrâncias inicial, intermediária e final.

\subsection{Instrumentos de coleta} de dados: desenvolvimento do questionário

Para a aplicação da pesquisa foi desenvolvido um questionário estruturado, com perguntas fechadas, contendo variáveis qualitativas ${ }^{12}$ e quantitativas ${ }^{13}$ capazes de permitir a descrição e análise dos objetivos específicos.

Inicialmente havia a proposta de encaminhar os questionários por mala direta, a todos os magistrados registrados no Tribunal de Justiça, com data préestabelecida para devolução. No entanto, contatos posteriores com o Departamento de Informática do Tribunal conduziram à opção pela disponibilidade de um questionário via "intranet", um método que pode ser considerado mais vantajoso sob o ponto de vista do custo econômico, do tempo de retorno e dos índices de cooperação dos informantes.
O questionário foi organizado em forma de blocos, com questões destinadas aos seguintes aspectos:

1. Identificação da comarca e unidade de trabalho;

2. Perfil do magistrado;

3. Atividades desenvolvidas;

4. Características físicas do ambiente de trabalho;

5. Opiniões a respeito das condições gerais de trabalho;

6. Percepções sobre a carga de trabalho.

Uma vez estabelecidas as perguntas e devidamente estruturado, o questionário foi testado junto a um grupo de cinco magistrados. Foi também realizada uma entrevista pessoal com os mesmos, no sentido de colher informações detalhadas a respeito das dificuldades encontradas no preenchimento, receber sugestões de alterações e dimensionar o tempo destinado ao preenchimento. Os resultados colhidos no teste de preenchimento e nas entrevistas pessoais foram incorporados ao questionário.

Após o período de teste e revisão do questionário, estabelecidos o seu conteúdo e formato final, o mesmo foi disponibilizado na "intranet" do Tribunal de Justiça, entre 8 horas do dia 29 de agosto e 12 horas do dia 08 de setembro de 2005, ou seja, durante 9 dias úteis.

12 Variáveis qualitativas são aquelas que tratam de atributos ou características não mensuráveis numericamente, como sexo, grau de instrução, tipos de processos em que atua, etc.

13 Variáveis quantitativas são aquelas que tratam de características mensuráveis numericamente, como idade, tempo de serviço, $\mathrm{n}^{\circ}$ de horas que dedica a alguma atividade, $\mathrm{n}^{\circ}$ de processos que recebe, etc. 
Neste período foram recebidos 185 questionários dos 771 cargos providos. Portanto, uma taxa de retorno de $24,0 \%$ por parte dos magistrados.

\subsection{Amostragem realizada}

As pesquisas onde não é possível selecionar, a priori, as pessoas que serão entrevistadas, são consideradas como não-probabilísticas. Pesquisas de opinião, eleitorais, de posicionamento de marca e várias outras, assim como a realizada pelo Tribunal de Justiça, enquadram-se nesta categoria.

Nesta pesquisa do Tribunal de Justiça, a realização de uma amostragem probabilística exigiria recursos e tempo muito superiores aos planejados, razão pela qual a equipe técnica do projeto decidiu por um método cujo custo atendia à limitação orçamentária, sem prejuízos com respeito a representatividade da amostra.

A amostra de 185 magistrados que responderam à pesquisa, dado o universo de 771 cargos providos, apresenta um erro de $2,94 \%$ para a média de horas semanais exclusivamente dedicadas às atividades que exigem intervenções diretas nos processos judiciais. Este erro encontra-se dentro de padrões aceitáveis para este tipo de estudo.

\subsection{Técnicas estatísticas utilizadas}

Para possibilitar uma análise de todas as informações solicitadas no questionário, foram elaboradas tabelas com os resultados encontrados indivi- dualmente para as variáveis e também para alguns cruzamentos entre variáveis.

Para as variáveis quantitativas foram calculadas médias, identificados os valores mínimos e máximos observados, e calculadas outras medidas estatísticas necessárias à análise dos dados. Para as variáveis qualitativas foram calculadas percentagens.

As variáveis escolhidas para avaliar o volume e a complexidade da atividade jurisdicional foram transformadas numa pontuação, capaz de permitir a sua classificação em ordem crescente.

\subsection{Indicadores utilizados para} medir a carga de trabalho dos magistrados

a) Número de tipos de processos em que o magistrado atua. Foi atribuído um ponto para os que atuavam em apenas um tipo de processo, dois pontos para os que atuavam em dois tipos, quatro pontos para os que atuavam em três ou quatro tipos, cinco pontos para aqueles magistrados que atuavam de cinco a sete tipos, seis para os atuantes entre oito e doze tipos, e finalmente sete pontos para os que atuavam em treze ou quatorze tipos de processos diferentes. Esta atribuição avalia apenas a complexidade da atividade exercida e não a complexidade do conteúdo do processo. A atuação em mais de um tipo de processo exige do magistrado conhecimento mais diversificado, logo, mais complexo e mais abrangente. Uma sentença num processo de execução criminal exige do magistrado conhe- 
cimentos diferentes daqueles necessários para uma sentença num processo de falência ou concordata. Assim sendo, quanto maior o número de tipos de processos no qual o magistrado atuava mais pontos the foram atribuídos.

b) Funções que exerce atualmente. Considerando as diversas funções exercidas pelos magistrados, foi atribuído um ponto para os que somente exerciam a função de pretor ou somente juiz de direito. Para os que exerciam as funções de pretor, juiz de direito, juiz eleitoral e diretor de foro foram atribuídos quatro pontos. Tal como ocorreu com o tipo de processo, também no caso das funções exercidas foi considerado um maior número de pontos para os que exerciam mais funções.

c) Total de horas semanais em atividades que exigem intervenções diretas nos processos judiciais: máximo de cinco pontos, atribuídos de acordo com a metodologia apresentada logo abaixo, que foi utilizada também para os indicadores 4, 5, 6 e 7 .

d) Total de horas semanais em atividades administrativas: máximo de quatro pontos.

e) Total de horas anuais em atividades de representação: máximo de quatro pontos.

f) Total de horas anuais em participações em congressos, simpósios, seminários e outras atividades de aperfeiçoamento, como ouvinte, oferecidos pelo $T J$ : máximo de quatro pontos.

g) Total de horas mensais em outras atividades: máximo de quatro pontos.
A atribuição de pontos para as horas de trabalho considerou a distribuição das horas encontrada para todos os magistrados da amostra, adotando-se sempre quatro faixas para cada indicador. Ou seja, as horas de trabalho respondidas pelos magistrados foram divididas em quatro faixas (por exemplo, $1^{\text {a }}$ faixa - 16 a 30 horas; $2^{\mathrm{a}}$ faixa -31 a 40 horas; $3^{\text {a }}$ faixa -41 a 50 horas; $4^{\text {a }}$ faixa - 51 a 60 horas). À primeira faixa foi atribuído um ponto, à segunda dois, à terceira três e à quarta faixa quatro pontos.

O uso da distribuição das horas efetivamente respondidas pelos magistrados da amostra, e não modelos que teorizam o número de horas que os magistrados deveriam cumprir em suas jornadas de trabalho, permitiu calcular a carga de trabalho efetivamente cumprida, tornando mais realista a avaliação que se deseja fazer.

h) Número de processos que recebe mensalmente. A atribuição de pontos para o número de processos que recebe mensalmente também considerou a distribuição dos valores encontrada para todos os magistrados da amostra. Para esta distribuição foram adotadas oito faixas. À primeira faixa foi atribuído um ponto, à segunda dois, e assim sucessivamente até a oitava faixa, que recebeu oito pontos.

i) Disponibilidade de pessoal. A pontuação para esta variável foi estabelecida em função dos pontos atribuídos ao indicador 8 "Número de processos que recebe mensalmente" e dos pontos atribuídos ao "número de assessorias". Na situação onde a pon- 
tuação do número de processos recebidos era baixa e a pontuação das assessorias alta, foi atribuído o escore -1 (menos um). Para uma pontuação do número de processos recebidos baixa e pontuação das assessorias também baixa, assim como, nas situações onde a pontuação do número de processos recebidos era alta e a pontuação das assessorias também alta, foi atribuído o escore 0 (zero). Na situação onde a pontuação do número de processos recebidos era alta e a pontuação das assessorias baixa, foi atribuído o escore +1 (mais um).

Considerando a metodologia de atribuição de pontos acima especificada, o máximo de pontos que um magistrado poderia atingir, somando a pontuação dos nove indicadores, seria de quarenta e um.

Neste caso extremo, o magistrado deveria ter informado que atuava em mais do que treze tipos de processos, exercia todas as funções que poderiam ser a ele atribuídas, ocupava sempre o número máximo de horas nas distribuições encontradas para o total de horas semanais dedicadas às atividades diretas nos processos judiciais, nas atividades administrativas, no total de horas mensais em outras atividades e no total de horas anuais de representação e participação em congressos.
Deveria também ter informado que recebia mensalmente acima de quatro mil processos, e o número de assessorias disponíveis era muito baixo.

Evidentemente tal situação extrema não ocorreu, chegando o número total de pontos para a carga de trabalho a um máximo de vinte e oito pontos e a um mínimo de três pontos. O número médio de pontos foi de dezessete, observando-se ainda que $50 \%$ dos magistrados da amostra alcançaram entre 17 e 28 pontos.

\subsection{Modelo geral da função "carga de trabalho"}

Considerando a "carga de trabalho" como variável dependente ${ }^{14}(\mathrm{Y})$, o seu resultado final é representado pela soma das pontuações das seguintes variáveis independentes ${ }^{15}(\mathrm{X})$ :

$X_{1}$ - Tipos diferentes de processos em que atua (variável "proxi" da complexidade da atividade);

$X_{2}$ - Funções que exerce atualmente;

$X_{3}$ - Carga horária total nas intervenções judiciais diretas;

$X_{4}$ - Carga horária total nas atividades administrativas;

$X_{5}$ - Carga horária total nas atividades de representação;

14 Variável dependente é aquela afetada ou explicada pelas variáveis independentes. Ou seja, seus valores irão variar de acordo com as mudanças nas variáveis independentes. 15 Variável independente é aquela que afeta ou explica as variações ocorridas na variável dependente. 
$\mathrm{X}_{6}$ - Carga horária nas atividades de aperfeiçoamento;

$\mathrm{X}_{7}$ - Carga horária nas outras atividades;

$\mathrm{X}_{8}$ - Número de processos que recebe mensalmente;

$\mathrm{X}_{9} \quad$ - Assessorias: disponibilidade de pessoal.

A soma total dos pontos atribuídos a cada magistrado para as nove variáveis independentes, foi então considerada uma estimativa da carga de trabalho. Segundo a metodologia adotada para avaliação da carga de trabalho, os magistrados com atuação em qualquer entrância tiveram a mesma probabilidade de atingirem o máximo de pontos encontrados, no caso, vinte e oito pontos. Assim sendo, e tendo em vista a não identificação dos magistrados que prestaram as informações, foi possível comparar as situações entre as entrâncias inicial, intermediária, final e foro central.

Estabeleceu-se ainda que o nível baixo de carga de trabalho seria atribuído aos informantes que atingiram valores abaixo de 10 pontos, o nível médio entre 11 e 19 pontos e o nível alto acima de 20 pontos.

\subsection{Apresentação dos resultados}

O primeiro objetivo do estudo era o de realizar o levantamento da percepção da carga de trabalho semanal dos magistrados de primeiro grau do Estado mediante questionários. $\mathrm{O}$ quadro a seguir expõe o resultado desta verificação das atividades inerentes ao cargo.

ro 6 - Carga de Trabalho dos Magistrados de $1^{\circ}$ Grau do Rio Grande do Sul

Atividades

Carga horária semanal média

49 horas e 45 minutos 2 horas e 16 minutos
1 hora
1 hora

54 horas

Total de horas semanais

005, p. 110

A partir dos dados acima, concluise que cada magistrado trabalha em média 54 horas semanais, dedicadas exclusivamente às atividades relacionadas ao exercício da magistratura. Em uma semana de 5 dias isto representaria quase 11 horas diárias. Em uma semana de 6 dias, em torno de 9 horas diárias.

Fica evidente que a carga de trabalho total dos Magistrados é excessiva e, basicamente, dedicada à intervenção direta nos processos judiciais (considerando uma carga horária semanal de 40 horas). Cabe a ressalva de que nestes itens não foi realizado o corte estatístico aplicado no último momento do estudo, mantendose os valores extremos que indicariam uma dedicação de meio-período (20 horas) ou até integral (70 horas) ou, novamente, um simples erro de preenchimento do questionário.

O levantamento da distribuição dos níveis de carga de trabalho segundo as entrâncias onde os magistrados de 
primeiro grau atuam era o segundo objetivo da pesquisa. cesso pode variar em grau de complexidade. Por exemplo, um processo criminal varia de um simples furto a um homicídio qualificado com necessidade de ouvir diversas testemunhas. Um processo de divórcio na Vara de Família e Sucessões pode variar de consensual, sem filhos e sem bens até um processo litigioso, com disputa pela guarda dos filhos e pela divisão de inúmeros bens. E assim por diante. Entretanto (e até por este motivo), cientes destas diferentes possibilidades, optou-se por calcular a variável complexidade da forma acima descrita.

O último dos objetivos específicos propostos na pesquisa foi o de estabelecer indicadores do número de processos recebidos e atendidos mensalmente, e como conseqüiência, estudar uma relação ideal entre o número de processos e o número de magistrados.

Para atingir esse objetivo foi utilizada a técnica estatística de estimação por intervalos de confiança, adequada ao estudo pelo fato de se trabalhar com amostra e não com a população total de magistrados da primeira instância.

Considerando a informação registrada nos questionários no que diz respeito ao número médio de processos que os magistrados atendem mensalmente, foi estabelecida uma metodologia no sentido de identificar os limites do número de processos que atende- 
riam considerando uma jornada de 40 horas semanais de trabalho.

A partir da carga horária semanal média de 54 horas, conforme resultados encontrados para as atividades diretas, administrativas, de representação, de aperfeiçoamento e de reuniões ou eventos externos, foi estabelecida uma proporcionalidade com o número de processos que atende mensalmente. Estabelecida a proporcionalidade para as 54 horas, foi calculado para cada um dos magistrados que responderam a pesquisa o número de processos que atenderia por mês caso a jornada de trabalho semanal fosse de 40 horas.

Devido a grande variabilidade encontrada no número de processos em todas as entrâncias analisadas, foi realizado um corte nos valores extremos inferiores e superiores não superior a $20 \%$ dos casos.

Os resultados, por entrância, são a seguir descritos (Costa; Michel; Michel, 2005).

a) Entrância Inicial: para uma média de 878 processos atendidos encontrou-se um intervalo de 715 a 1.040 processos, considerando uma probabilidade de confiança de $95 \%$. Isto significa a existência de um grau de crença de $95 \%$ de que o número médio de processos que um magistrado na entrância inicial tem condições de atender mensalmente é algum valor entre 715 e 1.040.

b) Entrância Intermediária: para uma média de 1008 processos atendidos encontrou-se um intervalo de 845 a 1.170 processos, considerando uma probabilidade de confiança de 95\%. c) Entrância Final: para uma média de 1.195 processos atendidos encontrouse um intervalo de 910 a 1.480 processos, considerando uma probabilidade de confiança de $95 \%$.

Com muito boa aproximação os valores acima calculados revelam uma situação ideal, pois foram determinados a partir de uma realidade informada pelos magistrados, e considerando uma carga horária legal de 40 horas semanais de trabalho.

\section{ANÁLISE COMPARATIVA DAS METODOLOGIAS EMPREGADAS}

A análise aqui proposta restringiuse a alguns modelos de cálculo de carga de trabalho aos quais foi possível obter acesso, em um dos casos de forma indireta, através da análise do pesquisador português Boaventura de Sousa Santos. Embora cientes das limitações que tal abordagem representa, julgou-se relevante a discussão das peculiaridades de cada método, como subsídio para futuras pesquisas e consultas. Os métodos quantitativos e qualitativos, as técnicas mistas, os diferentes grupos amostrais, as variáveis selecionadas e as fórmulas de cálculos fazem destes estudos uma fonte de consulta rica, porém difícil.

Inicialmente os estudos apresentaram várias diferenças quanto ao âmbito de análise. O estudo do STF possui uma extensão nacional, pois compreendeu dados de todos os Tribunais Estaduais e Federais. O estudo espanhol 
também possui tal abrangência, pois os módulos de trabajo são elaborados de forma a determinar a carga máxima de trabalho suportável de um órgão judicial. Os estudos portugueses trabalharam com magistrados de tribunais cíveis e criminais de algumas localidades somente, e não de todo o país. Já a pesquisa realizada para o Tribunal de Justiça do Rio Grande do Sul teve o seu âmbito restrito aos magistrados de primeiro grau do Estado. Os métodos apresentados no estudo americano Assessing the need for judges and court support staff foram elaborados considerando a realidade das justiças estaduais. O The Case-Related Workload Measures foi elaborado considerando a produtividade dos magistrados federais norte-americanos.

Em razão desta diferença de âmbitos, os focos das metodologias apresentadas e as medidas utilizadas para a avaliação da carga de trabalho dos magistrados também são distintas. O estudo do Hay Group considera a complexidade dos processos judiciais, a capacidade física instalada, os recursos humanos disponíveis, a experiência do magistrado, o número de horas de trabalho disponíveis e o tempo dedicado à atividade jurisdicional. Com essas variáveis sugere uma fórmula para determinar a carga de trabalho adequada aos magistrados criminais. Já o estudo coordenado por Boaventura de Souza Santos classificou as diversas intervenções realizadas por magistrados em algumas categorias de processos cíveis, de modo a encontrar o tempo esperado para a ação do magistrado em cada um dos tipos de processos selecionados, considerando o peso de cada tarefa nos processos.

O detalhamento das intervenções processuais realizadas pelos magistrados e o tempo necessário para tal, e a ponderação das tarefas processuais e dos tipos de processos também são recomendadas no estudo norte-americano do NCSC. Por fim, o estudo recomenda, para verificar a necessidade de magistrados, a divisão do tempo total exigido para apreciar determinado tipo de processo pelo tempo disponível pelo magistrado para apreciação de processos. Já o sistema do The CaseRelated Workload Measures foi estruturado inicialmente considerando somente os tempos dedicados aos processos pelos magistrados, de modo a elaborar os valores temporais referenciais para o limite da carga de trabalho. Posteriormente o número de atividades em que o magistrado se envolve considerado foi expandido, de modo a incluir outras atividades como a participação de audiências e realização de despachos.

O material disponível relativo aos módulos de trabajo não permitiram o conhecimento preciso da forma que o órgão de cúpula sobre gestão do Poder Judiciário espanhol estabelece o número ideal de processos. Os dados disponíveis simplesmente indicam que o volume de processos acima do estabelecido é o indicador de que a carga de trabalho é excessiva.

A fórmula proposta pelo Supremo Tribunal Federal e adotada posterior- 
mente pelo Conselho Nacional de Justiça trabalha somente com dados quantitativos: casos novos, casos pendentes de julgamento, processos já sentenciados em execução e número de magistrados.

O estudo gaúcho trabalhou com variáveis diversas: o tempo médio percebido pelos magistrados despendido na intervenção de processos, atividades administrativas, aperfeiçoamento, representação e outras; além de considerar a infra-estrutura material e humana, a entrância, o número de processos recebidos e os tipos de processos em que atua. De tais elementos foram calculadas as médias, valores mínimos e máximos, as percentagens e a pontuação das variáveis escolhidas, de modo a possibilitar a avaliação do volume e da complexidade do trabalho por entrância de atuação.

Em que pesem as diferenças expostas, todos os estudos objetivaram estimar qual a carga de trabalho adequada para o número de magistrados disponíveis em cada realidade analisada, com vistas ao dimensionamento do quadro de magistrados e ao planejamento da distribuição de processos. Destacase como objetivos adicionais relevantes os do estudo do STF, cujo objetivo principal foi a criação de indicadores nacionais de gestão, de modo a identificar os "gargalos" e causas para a lentidão do Judiciário brasileiro.

Acredita-se que nenhum dos estudos acima apresentados está isento de imperfeições. O método Weighted Caseload, conforme analisado por
Flango e Ostrom (1996) apresenta dificuldades na obtenção da cooperação dos magistrados para apurar os tempos médios, no mapeamento das diferentes realidades de comarcas distintas, na atribuição e atualização dos pesos, o rebaixamento das cargas médias desejáveis, entre outros problemas já especificados na seção 2.1. deste ensaio. O mesmo ocorre com o método espanhol que, embora apresente o mérito de tentar definir indicadores de desempenho e de qualidade, também ignora a realidade do judiciário espanhol e suas características distintas. O estudo do Hay Group não considerou a realização de qualquer análise do trabalho efetivamente desenvolvido pelos magistrados nos processos (SANTOS, 2005). O estudo da faculdade de Economia da Universidade de Coimbra, da mesma forma que o estudo do Tribunal de Justiça do Estado do Rio Grande do Sul, identificou o tempo percebido pelos respondentes e não o tempo real de cada intervenção judicial. O estudo do Supremo Tribunal Federal contabilizou, em um primeiro momento, os processos em fase de execução, cujo andamento não estava mais a cargo dos magistrados, gerando uma taxa de congestionamento irreal. Além disso, também não considerou as diferentes características regionais.

Finalmente, intriga os autores deste ensaio os resultados discrepantes dos métodos empregados. De acordo com os estudos acima apresentados, um magistrado norte-americano das cortes correspondentes ao primeiro grau brasi- 
leiro deve atuar com um limite de 430 processos anuais. Já os espanhóis enfrentam uma demanda de 1.493 processos/ano para cada magistrado. Os portugueses oscilam entre 180 a 460 processos anuais, em números aproximados. Entretanto, os brasileiros chegam a enfrentar quase 24.000 processos anuais no Supremo Tribunal Federal e quase 29.000 na Justiça Federal - Juizados Especiais (pesquisa do STF). O estudo do TJ-RS também é alarmante para os brasileiros: os magistrados afirmam trabalhar numa jornada de 54 horas semanais para tentar dar conta de um número aproximado de 13.500 processos/ano. Quando questionados sobre o número de processos desejável para um magistrado atender anualmente, com a qualidade e a rapidez que a sociedade espera, os magistrados apontaram que a carga atual de trabalho é cinco vezes superior à que se pode suportar.

\section{CONSIDERAÇÕES FINAIS}

\subsection{Limitações do ensaio}

Este ensaio apresenta algumas limitações no sentido de que não foi possível conhecer a íntegra de todos os estudos comparados. Além disso, a análise carece do conhecimento de eventuais estudos que possam ter sido realizados (ou ainda estejam sendo postos em prática) em um maior número de países, incluindo países da América Latina, com contextos possivelmente mais próximos da realidade brasileira.
Poderia auxiliar na compreensão da aplicação das metodologias descritas, a apresentação completa dos resultados de cada um dos estudos realizados. Entretanto, o volume de informações geradas a partir dos diferentes estudos inviabilizou sua inserção no espaço deste ensaio.

\subsection{Conclusões e recomendações}

A realização dos estudos citados demonstra a premência de desenvolvimento de um método confiável de avaliar a carga de trabalho de magistrados com os objetivos de: a) evitar cargas elevadas ou reduzidas; b) distribuir os processos a cada magistrado a partir de critérios justos e transparentes; c) planejar as necessidades de aporte de recursos humanos, materiais, técnicos, informacionais e logísticos; d) permitir a gestão estratégica da Justiça; e e) qualificar cada vez mais a prestação jurisdicional.

Não há, no entender dos autores e até o momento, algum método que dê conta da complexidade da questão. Ficou claro que a carga não está relacionada somente ao número de processos, mas às questões jurídicas (como a existência de regulamentos internos que muitas vezes ocasionam entraves na celeridade do andamento dos processos e a possibilidade do ingresso de recursos que aumentam a demanda do segundo grau), à complexidade dos processos, às demandas e características culturais da população a qual o Judiciário atende, além da infra-estru- 
tura disponível, ao perfil do conjunto de magistrados e do pessoal de apoio entre outras variáveis.

Qualquer estudo que não considere a complexidade do tema poderá chegar a conclusões simplistas.

Concluiu-se também que os métodos de levantamento de carga de trabalho dos magistrados e seus resultados não devem ser utilizados com o propósito de geração de "rankings de produtividade", próprios dos modelos da gestão privada. Esta inadequação se deve às diferenças básicas entre o público $\mathrm{e}$ o privado: a) o serviço público, com seus objetivos exclusivos de atendimento às demandas dos cidadãos com a máxima qualidade possível, dentro de prazos delimitados, ensejando mecanismos de planejamento e de controle próprios; $b$ ) a complexidade das interfaces com a sociedade, e com os demais poderes; e c) as exigências legais.

É preciso uma ação sistêmica que repense as relações entre os poderes, os controles e leis de tramitação processual, o número de recursos possíveis, entre diversos outros fatores.

Do ponto de vista das fórmulas de cálculo da carga de trabalho e considerando que a pesquisa do Tribunal de Justiça do Estado do Rio Grande do Sul revelou muitos casos de respostas discrepantes, uma recomendação que pode ser feita é a implantação, com maior ênfase e imposição, dos atuais mapas de atividades. Tais mapas que deveriam ser planejados no sentido de permitirem análises futuras mais detalhadas dos procedimentos e tempos dedicados a cada tipo de processo. Não é possível atingir resultados mais precisos na análise de dados onde não se dispõem de um conjunto de informações uniformes, sistemáticas e confiáveis.

Em relação às demais metodologias apresentadas, sugere-se a adoção daquelas que, a exemplo dos estudos do Tribunal de Justiça do Rio Grande do Sul, do Hay Group e do Delphi Method, considerem a percepção dos magistrados acerca de suas próprias atividades em combinação com métodos de aferição dos tempos dos atos processuais (utilizados nos estudos norteamericanos), a fim de reduzir a margem de erros nos levantamentos e de incluir variáveis contextuais. Havendo recursos para tanto, a constituição de amostras estratificadas pode ser importante no apoio ao detalhamento de diferentes contextos. Por outro lado, um estudo como o do TJ, que não fez uso deste tipo de amostra, pode representar um primeiro passo no mapeamento geral do quadro de carga de trabalho de um local determinado - como foi o caso do Rio Grande do Sul - e abrir perspectivas interessantes para novos estudos (como é o caso dos estudos exploratórios). A perspectiva do estudo espanhol de construir indicadores de desempenho e de resultados é bastante louvável e sugerese seja considerada com o intuito de que não se esqueça de que a exigência por celeridade poderia, hipoteticamente, comprometer a qualidade.

A análise de estudos internacionais e nacionais pode vir a representar uma primeira aproximação entre instituições de diferentes âmbitos na busca de 
indicadores confiáveis, considerando-se as diferenças locais, que talvez lancem luz sobre as brutais diferenças das cargas de trabalho dos magistrados brasileiros e de seus pares espanhóis, portugueses e norte-americanos.

Cabe ressaltar que a tentativa de mensuração dos padrões de produtividade ideais não é recente. No início do século passado Frederick W. Taylor (1990), conhecido hoje como o "Pai da Administração Científica", buscou definir a produtividade do que ele considerou o "trabalhador médio" para, a partir daí, poder recompensar os que excedessem este padrão. Diversas críticas são feitas ao seu trabalho até hoje, entre as quais a de que o "trabalhador médio" não representava a média dos esforços dos operários, mas sim, um desempenho excepcional de um homem excepcionalmente forte e rápido.

\section{REFERÊNCIAS}

BRANCHER, Leoberto N. Reconfiguração do Sistema de Justiça da Infância e da Juventude na Execução de Medidas Sócio-Educativas. Porto Alegre: Poder Judiciário do Estado do Rio Grande do Sul, 1998. (Relatório Técnico da $3^{\text {a }}$ Vara do Juizado da Infância e da Juventude).

BRANCHER, Leoberto N.; COSTA, Sílvia Generali. Visão Sistêmica da Implementação e da Gestão da Rede de Atendimento Projetada pelo Estatuto da Criança e do Adolescente. Porto Alegre: Poder Judiciário do Estado do Rio Grande do Sul, 1998. Relatório Técnico da
O que se quer destacar, por fim, é que a definição da carga de trabalho ideal não é, e nem nunca será, um critério totalmente objetivo no sentido da objetividade das ciências exatas. Critérios políticos, ideológicos, e pressupostos pessoais acerca da natureza humana e do trabalho sempre terão influência sobre o tema. Fatores dinâmicos, como as influências culturais, sociais, demográficas, econômicas e políticas irão sempre interferir na percepção e, conseqüentemente, na avaliação da carga de trabalho. Entretanto, o desenvolvimento de um método que permita o mapeamento, o mais próximo possível, do dia-a-dia dos magistrados e de suas condições de trabalho pode contribuir fortemente para a maior excelência na administração judiciária e para qualificar ainda mais o atendimento à sociedade.

$3^{\text {a }}$ Vara do Juizado da Infância e da Juventude.

CANAL JUSTIÇA. Fórum Nacional de Comunicação e Justiça. Jobim analisa indicadores da Justiça Federal. Disponível em: <http:// www.canaljustiça.jor.br/ index.php? $\mathrm{id}=14179>$. Acesso em: 14 dez. 2004.

CONSELHO NACIONAL DE JUSTIÇA. A Justiça em Números: Indicadores Estatísticos do Poder Judiciário 2004. Disponível em: $<$ http://www.cnj.gov.br/downloads/ JN2.pdf $>$. Acesso em: 16 set. 2006. 
CORDEIRO, Roberto. Ministro Vidigal diz em Fortaleza que desconhece pesquisa do STF. Notícias do Superior Tribunal de Justiça. Disponível em: $<$ http://www.stj.gov. br/webstj/Noticias/imprime_noticia. asp? seq noticia $=13942>$. Acesso em: 18 maio 2005.

COSTA, Silvia Generali; MICHEL, Nelson; MICHEL, Renato. Análise da Carga e da Distribuição de Trabalho no Poder Judiciário do Estado do Rio Grande do SulMagistrados e Servidores da Justiça de Primeiro Grau. Porto Alegre: Tribunal de Justiça, 2005. Relatório de Pesquisa.

ESPANHA. Consejo General del Poder Judicial. Acuerdo de 3 de diciembre de 2003, del Pleno del Consejo General del Poder Judicial, por el que se aprueba el Reglamento 2/2003, para el cumplimiento de la Ley $15 /$ 2003 , de 26 de mayo, reguladora del régimen retributivo de las Carreras Judicial y Fiscal, en lo relativo a las retribuciones variables por objetivos de los miembros de la Carrera Judicial. Disponível em: <http:// www.juecesdemocracia.es/pdf/ \#search $=\% 22 \% 22 \mathrm{~m} \% \mathrm{C} 3 \%$ B3dulos $\% 20$ de $\% 20$ trabajo $\% 20$ de $\% 20$ jueces $\% 20 \mathrm{y} \% 20$ magistrados $\% 22 \% 22>$. Acesso em: 06 set. 2006.

FLANGO Victor E.; OSTROM, Brian J. Assessing the Need for Judges and Court Support Staff. National Center for State Courts, 1996. Disponível em: <http://www.ncsconline.org/ WC/Publications/Res WorkLd AssessNeedsJudges\&StaffPub.pdf $>$. Acesso em: 15 set. 2006.

HAY GROUP. Estudo sobre Contingentação Processual, visando a definição de indicadores fiáveis sobre o volume de serviço adequado para cadajuiz dos tribunais judiciais. Lisboa: 2002.

LACOMBE, Francisco; HEILBORN, Gilberto. Administração: princípios e tendências. São Paulo: Saraiva, 2003.

LÁZARO, Julio M. El Supremo anula el sistema de control de la productividad judicial. El País, 23 fev. 2006. Disponível em: http://www.elpais.es/ articulo/espana/Supremo.Acesso em: 06 set. 2006.

NANCI, Luciana. Produtividade do Judiciário: Governo é principal responsável por lentidão da Justiça. Revista Consultor Jurídico. Disponívelem: <http://64.207.161.190/ novo/static/text $/ 34664,1>$. Acesso em: 18 maio 2005.

NATIONAL CENTER FOR STATE COURTS - NCSC. Workload and Resource Assessment - FAQs. Disponivel em : <http://www. ncsconline.org/WC/FAQs/ WorkLdFAQ.htm>. Acesso em: 15 set. 2006.

OLTRAMARI, Alexandre. O raio-x da Justiça. Revista Veja, edição 1904, 11 de maio de 2005. Disponível em: $<$ http://veja.abril.com.br $>$. Acesso em: 23 maio 2005.

RIFKIN, Jeremy. O Fim dos Empregos: o declínio inevitável dos niveis dos empregos e a redução da força global de trabalho. Tradução Ruth Gabriela Bahr. São Paulo: Makron Books, 1995.

RIO GRANDE DO SUL. Tribunal de Justiça. Relatório Anual 2004. Disponível em: <http://www.tj. rs.gov.br/institu/contas/r_anual/ rel2004/rel_2004.html>. Acesso em: 08 set. 2005 . 
- Plano de Gestão Pela Qualidade do Judiciário. Disponível em: <www.tj. rs.gov.br>. Acesso em: 26 dez. 2005.

SADY, João José. Divisão Errada: distribuição desigual de processos atrasa a Justiça. Revista Consultor Juridico, 13 maio 2005. Disponível em: <http://conjur.estadao.com.br>. Acesso em: 19 ago. 2005.

SALGADO, Solange. Justiça em Números: Levantamento do STF fez retrato distorcido do Judiciário. Revista Consultor Jurídico, 21 maio 2005. Disponivel em: <http://conjur.estadao. com.br>. Acesso em: 19 ago. 2005.

SANTOS, Boaventura de Sousa (dir. científico). Os actos e os tempos dos juízes: contributos para a construção de indicadores da distribuição processual nos juizos civeis. Lisboa, 2005. Disponível em: <http:// opj.ces.uc.pt/portugues/relatorios/ relatorio_Actos $\% 20 \mathrm{e} \% 20$ tempos. html>. Acesso em: 20 maio 2006.

SUPREMO TRIBUNAL FEDERAL. Seminário A Justiça em Números Indicadores Estatísticos do Poder Judiciário Brasileiro 2003. Disponível em: <http://www.stf. gov.br/seminario/>. Acesso em: 16 set. 2006.

TAYLOR, F. W. Princípios de Administração Científica. Tradução Arlindo Vieira Ramos. 8. ed. São Paulo: Atlas, 1990. 


\section{$\mathbf{M}+$ \\ editoracto eletrónica}

513222.5044

vmm.ez@terra.com.br

Composto especialmente para a Editora Meridional, em Times New Roman, corpo 11/13,5, sobre o papel offset $75 \mathrm{~g}$

e impresso na

\section{/AETRÓPOLLE \\ www graficametropole com br




\section{Revista da \\ Faculdade de Direito UFRGS}

Av. João Pessoa, n. 80 - CEP 90.040-000 - Porto Alegre/RS - Brasil

Tel: (51) $3316.3118 / 3316.3128 / 3316.3555 / 3316.3464$

\section{DISTRIBUIDORES / REPRESENTANTES}

AMAZONAS - Travessia Editora e Livraria Ltda. - Valer Livraria - Fone/fax: (92) 3633-6565 Editora Vozes Ltda. - Fone: (92) 3232-5777

BAHIA / SERGIPE - LDM - Livraria e Distribuidora Multicampi Ltda. - Fone: (71) 2101-8000 CEARÁ - Livraria Marques Mariano Ltda. Lua Nova - Fones: (85) 3223-4336 / 3214-5488

DISTRITO FEDERAL - J. Quinderé Distribuidora de Livros Ltda. - Fones: (61) 3347-8461 / 3347-7386 Livraria Cultura S/A - Casapark Shopping Center - Fone: (61) 3410-4033

Editora Vozes Ltda. - Fone: (61) 3326-2436

GOIÁS - Editora Vozes Ltda. - Fone: (62) 225-3077

ESPIRITO SANTO - Representações Paulista Ltda, - Logos Livraria - Fone: (27) 3137-2568

MINAS GERAIS - Alpha Distribuidora de Livros Ltda. - Fones: (31) 3497-9179 / 3497-1939

PARAÍBA - UFPB - Universidade Federal Paraiba - Casa do Livro - Fonelfax: (83) 3216-7327

PARANÁ - Aramis Chain - Fone: (41) 3264-3484

Berton \& Cosmo Ltda. - Fone/fax: (41) 3213-5600

Editora Vozes Ltda. - Fone/fax: (41) 3233-1392

PERNAMBUCO - Potylivros Distribuidora Ltda. - Fone/fax: (81) 3423-1100

Livraria Cultura S/A - Fone: (81) 2102-4033

Editora Vozes Ltda. - Fone: (81) 3423-4100

RIO DE JANEIRO - Mazolli \& Assis Comércio de Livros Ltda. - Odisséia - Fones: (21) 2290-0873 / 2290-1305

Livraria da Travessa S/A - Ipanema - Fone: (21) 3205-9002 Ramais: 247 e 239

Editora Vozes Ltda. - Fone/fax (21) 2533-8358

RIO GRANDE DO NORTE - Potylivros Distribuidora Ltda. - Fonelfax: (84) 3203-2626

RIO GRANDE DO SUL - Multilivro Distribuidora e Livraria Ltda. - Fones: (51) 3223-7363 / 3223-6622 Livraria Cultura SIA - Bourbon Shopping Country - Fone: (51) 3028-4033

SANTA CATARINA - Livraria Livros \& Livros Ltda. - Fone/fax: (48) 3028-6244

SÃO PAULO - Batatais Comércio e Represent. de Livros Ltda. - Fones (11) 3266-3097 / 3266-2976

Empório do Livro Editora e Livraria Ltda. - Fones: (11) 3255-1447 / 3151-6401

EDUSP - Editora Universidade de São Paulo - Fone: (11) 3091-4409

Lerlivros Distribuidora Ltda. - Potyguar - Fone: (11) 3828-2423

Livraria Cultura S/A - Conjunto Nacional - Fone: (11) 3170-4033

Livraria Cultura S/A - Shopping Villa Lobos - Fone: (11) 3024-3599

Livraria Cultura S/A - Market Place - Fone: (11) 3474-4033

TOCANTINS - S.G.Vieira - Livraria Palmas Cultural - Fones: (63) 3215-3123 / 3225-5217

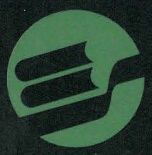

Editora Sulina

www.editorasulina.com.br

ISSN $0104660-8$ 